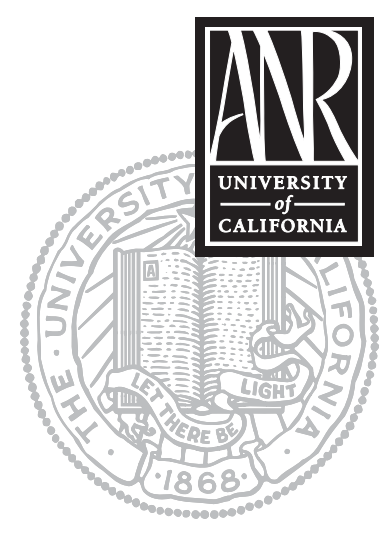

UNIVERSITY OF CALIFORNIA

Division of Agriculture and Natural Resources http://anrcatalog.ucdavis.edu

\title{
Footbaths for Animal Facilities: Easier Than You Think!
}

BRIGID A. MCCREA, Postdoctoral Employee, Department of Animal Science, University of California, Davis; FRANCINE A. BRADLEY, UCCE Poultry Extension Specialist, UC Davis

\section{WHAT LURKS ON THE SOLES OF MAN}

Did you know that humans are often the main reason for the spread of disease? Human footwear-the "sole" of the problem-is often not cleaned. Biosecurity involves training people and managing risk so that farmers do not unintentionally introduce disease to their livestock. Some organisms can live for days or weeks in dust and dirt, both of which stay on footwear. Footbaths are an easy, inexpensive, and an extremely valuable element of farm biosecurity. Biosecurity is a mindset: learn how to use it for the benefit of farm animals.

\section{FOR BIOSECURITY PURPOSES STEP INTO FOOT BATH BEFORE PROCEEDING}

Figure 1. Sample biosecurity sign.

\section{KEYS TO FOOTBATH SUCCESS: LOCATION, LOCATION, LOCATION}

Closely examine the traffic patterns in and around the area where animals are housed. Place the footbath in a location where everyone who comes into the farm must pass through. Post a sign (fig. 1) indicating that footbaths must be used and give directions on proper cleaning methods. If possible, place the footbath on a solid surface such as concrete, brick, or cinder block. This will allow people to use the footbath without creating mud in the area. A solid surface can also be swept or hosed to eliminate the buildup of dirt that can quickly pollute a footbath.

\section{EQUIPMENT}

- A tray with short sides, such as those used to bus tables in restaurants or a cat litter pan (fig. 2).

- A long-handled utility brush (fig. 3).

- A hose or spigot for mixing new batches of disinfectant (fig. 4).

- A small synthetic bristle or "fake grass" doormat (fig. 5).

- Depending on the location and the type of disinfectant used, a plastic lid may be needed to prevent contamination or inactivation of the disinfectant. A plastic storage container (whose sides are not transparent) with a lid may be beneficial (fig. 6).

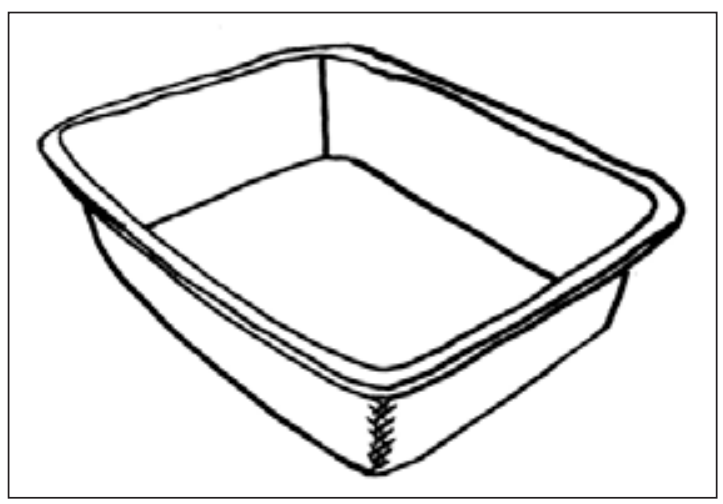

Figure 2. A cat litter pan is a good size for use as a footbath. 


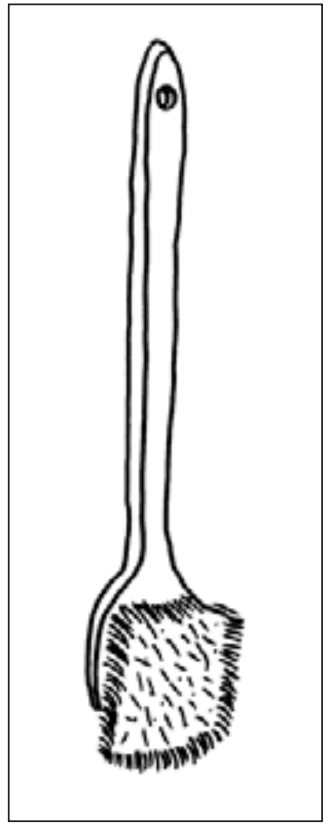

Figure 3. Long-handled utility brush

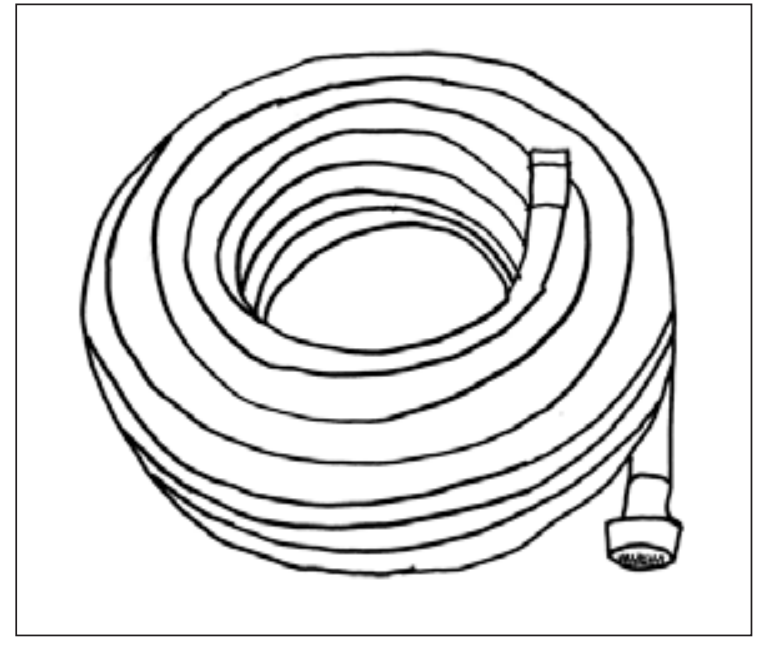

Figure 4. A hose is handy for mixing disinfectant.

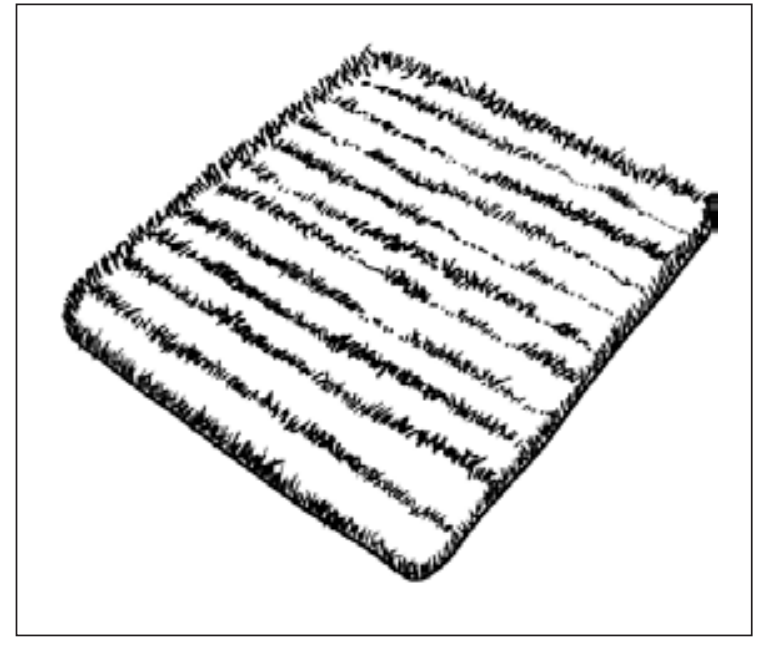

Figure 5. A mat should be used in the bottom of the footbath.

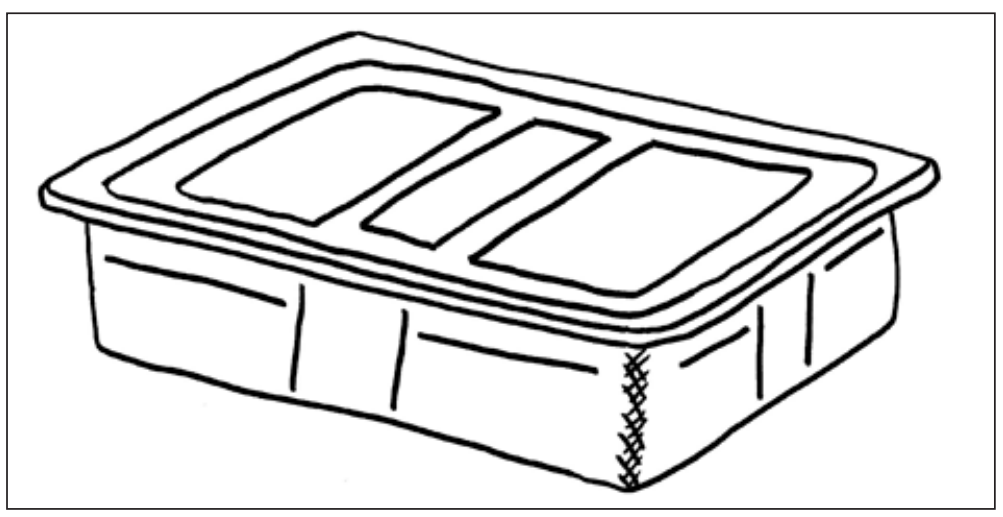

Figure 6. A covered container with opaque sides is another option for a footbath.

\section{SETTING UP THE FOOTBATH}

To set up the footbath, place the plastic container in the selected location. Cut the mat to fit inside the plastic container (fig. 7). Mix the disinfectant according to label directions and hang the long-handled utility brush within reach. Post directions and signs at eye level and indicate how old footbath disinfectant should be disposed. Train people in the proper way to use the footbath (see "How to Use a Footbath," below).

\section{DISINFECTANTS}

- Always mix disinfectants according to the label directions.

- Post directions on how to mix disinfectants.

- Select a disinfectant that kills bacteria as well as viruses.

- Keep in mind that some disinfectants are inactivated by sunlight or may have other requirements. For more information on disinfectants, see PFS No. 27: Sanitation-Disinfection Basics ( http://animalscience.ucdavis.edu/Avian/pfs27.htm).

- Most disinfectants can be ordered online or from your local feed store.

- Recommended disinfectants (fig. 8) include

- Tek-Trol, made by AgriLabs

- 1-Stroke Environ, made by Steris 


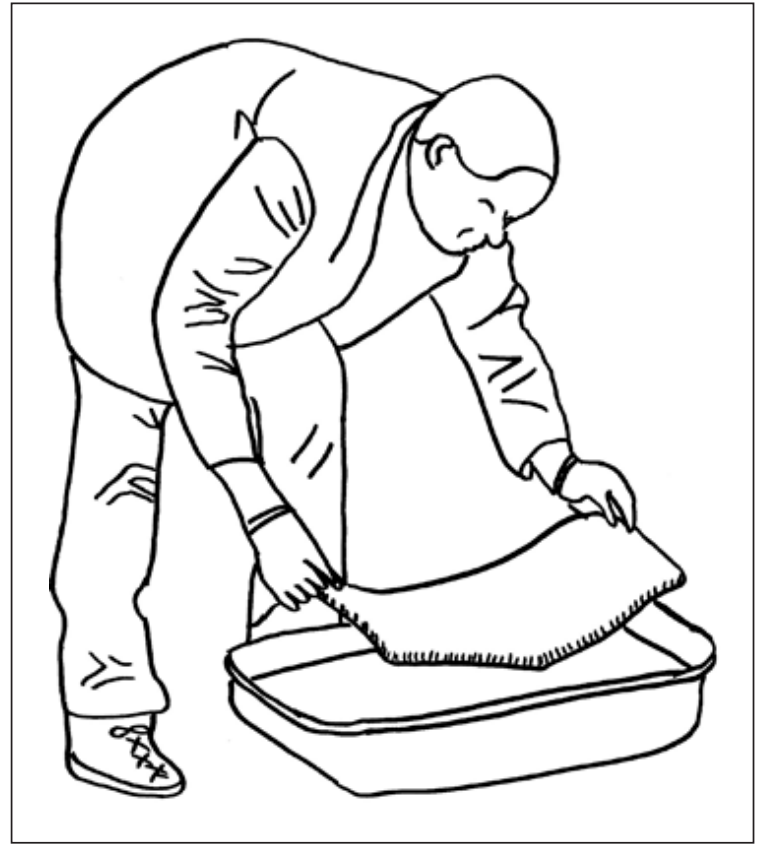

Figure 7. Footbath in preparation.

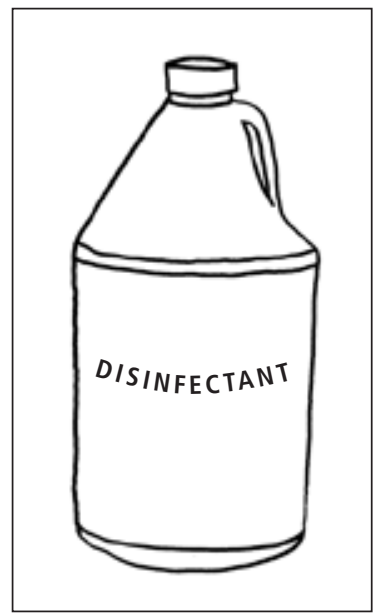

Figure 8. Disinfectant in a gallon-size container

\section{HOW TO USE A FOOTBATH}

Appropriate footwear must be worn through a footbath. Flipflops or sandals are popular in the summer, but they should not be worn through a footbath. Read the disinfectant label carefully and inform all who use the footbath about the risks of exposure to skin. The use of plastic or rubber overshoes is strongly recommended for wearing in a footbath. If footwear is soiled when entering a footbath, the disinfecting process will be ineffective. Dedicated overshoes (plastic or rubber) should be available at the footbath for both farm guests and regular users to wear through the footbath and on the farm. Expensive footwear probably should not pass through a footbath where staining or bleaching could occur. Read disinfectant labels carefully and follow any precautions.

Remove all debris from shoes before entering the footbath. Debris includes sticks, leaves, mud, or large quantities of manure. Debris on shoes reduces the effectiveness of the disinfectant. Provide a hose in inclement weather to remove mud from shoes.

When stepping into the footbath, immerse the whole tread of the shoe into the fluid. Rub shoes vigorously on the plastic mat to ensure that the entire sole is scrubbed thoroughly. Use a long-handled brush as needed. Disinfectant should be left on the footwear after passing through the footbath (fig. 9).

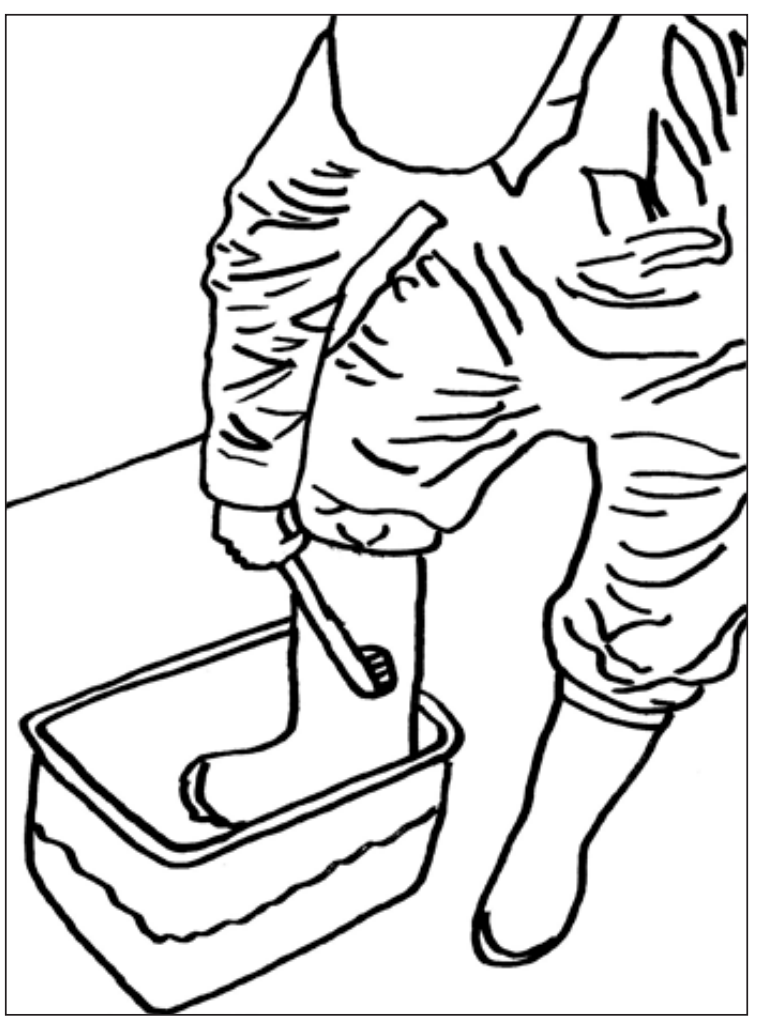

Figure 9. Footbath in use. 


\section{MAINTAIN YOUR FOOTBATH}

Footbaths should be cleaned as soon as the fluid begins to appear dirty; this often means weekly cleaning. Follow label instructions when disposing of used disinfectant. Footbaths should not be emptied in the immediate area of the wash station to prevent a wet, muddy area from developing. Scrub the empty container and mat with a brush and rinse them thoroughly. Add fresh disinfectant and place the mat back into the footbath. Hanging a long-handled brush near the footbath allows users to adequately clean the footbath as well as their footwear.

\section{A HANDY ALTERNATIVE}

If someone protests about using a footbath, have disposable plastic boot covers or overshoes for them to wear. These cost very little and are an effective biosecurity tool.

\section{HOW MUCH WILL A FOOTBATH COST?}

\begin{tabular}{lr} 
Cat litter pan & $\$ 4.50-8.50$ \\
Mat & $\$ 6.50-9.00$ \\
Long-handled utility brush & $\$ 5.50-6.00$ \\
Disinfectant (1 gal) & $\$ 27.00-37.00$ \\
\hline Total & $\$ 43.50-60.50$
\end{tabular}

\section{CONCLUSION}

Creating a footbath is not as difficult as one may think. The setup and maintenance of a footbath is straightforward and simple. The cost of setting one up is well worth the effort when compared with the cost of replacing all the animals on a farm or paying veterinary bills due to illness. Depending on the location, it may be prudent to provide more than one footbath (i.e., for main entrances and separate quarantine areas). Many owners have rare genetic lines of livestock and want to provide their animals with the best care, so farm managers should make sure that effective biosecurity steps are being taken to prevent the introduction of disease.

\section{RESOURCES}

Grooms, D., and D. Ross 2001. Biosecurity starts with your feet. Michigan Dairy

Review 6(4): 3-5; http://www.msu.edu/user/mdr/archives/mdrvol6no4.pdf.

Poultry Fact Sheet (PFS) No. 27: Sanitation-disinfection basics. UC Poultry Web Page, http://animalscience.ucdavis.edu/Avian/pfs27.htm.

USDA biosecurity guide for poultry and bird owners. Program Aid no. 1885, 2006. Animal and Plant Health Inspection Service (APHIS) Web site, http://www. aphis.usda.gov/publications/animal_health/content/printable_version/USDA_ BioGuide_Eng_8-2006.pdf. 
FOR FURTHER INFORMATION

To order or obtain ANR publications and other products, visit the ANR Communication Services online catalog at http://anrcatalog.ucdavis.edu. You can also place orders by mail, phone, or FAX, or request a printed catalog of our products from

\author{
University of California \\ Agriculture and Natural Resources \\ Communication Services \\ 6701 San Pablo Avenue, 2nd Floor \\ Oakland, California 94608-1239 \\ Telephone 1-800-994-8849 \\ (510) 642-2431 \\ FAX (510) 643-5470
}

E-mail: danrcs@ucdavis.edu

An electronic version of this publication is available on the ANR Communication Services Web site at http://anrcatalog.ucdavis.edu.

\section{Publication 8281}

ISBN 13: 978-1-60107-525-3

This publication has been anonymously peer reviewed for technical accuracy by University of California scientists and other qualified professionals. This review process was managed by the ANR Associate Editor for Animal, Avian, and Aquaculture Sciences.

(C)2008 The Regents of the University of California

Division of Agriculture and Natural Resources

All rights reserved.

No part of this publication may be reproduced, stored in a retrieval system, or transmitted, in any form or by any means, electronic, mechanical, photocopying, recording, or otherwise, without the written permission of the publisher and the authors.

The University of California prohibits discrimination or harassment of any person on the basis of race, color, national origin, religion, sex, gender identity, pregnancy (including childbirth, and medical conditions related to pregnancy or childbirth), physical or mental disability, medical condition (cancer-related or genetic characteristics), ancestry, marital status, age, sexual orientation, citizenship, or status as a covered veteran (covered veterans are special disabled veterans, recently separated veterans, Vietnam era veterans, or any other veterans who served on active duty during a war or in a campaign or expedition for which a campaign badge has been authorized) in any of its programs or activities. University policy is intended to be consistent with the provisions of applicable State and Federal laws.

Inquiries regarding the University's nondiscrimination policies may be directed to the Affirmative Action/Staff Personnel Services Director, University of California, Agriculture and Natural Resources, 1111 Franklin Street, 6th Floor, Oakland, CA 94607-5201, (510) 987-0096. For information about ordering this publication, telephone 1-800-994-8849.

To simplify information, trade names of products have been used. No endorsement of named or illustrated products is intended, nor is criticism implied of similar products that are not mentioned or illustrated.

pr-3/08-SB/RW 